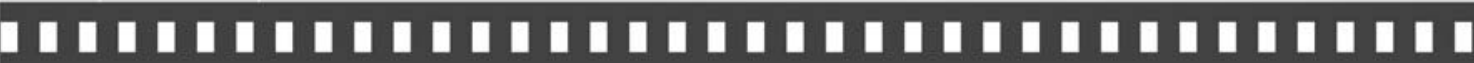

\author{
Entrevista: \\ Luis Humberto
}

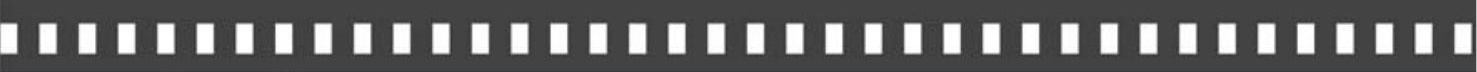

Simonetta Persichetti 


\section{Olhos Livres*}

\section{Simonetta Persichetti ${ }^{* *}$}

É quase impossível falar em fotojornalismo no Brasil sem citar o papel de Luis Humberto no desenvolvimento dessa linguagem. Tanto do ponto de vista prático - como fotógrafo que registrou momentos importantes de nossa história recente para Veja, IstoÉ ou Jornal de Brasília - como do ponto de vista teórico - ao levar, em 1987, o fotojornalismo para as carteiras escolares e para a discussão acadêmica. Não podemos esquecer que ele foi co-fundador da Universidade de Brasília (UnB), em 1962, e do Instituto Central de Artes da mesma instituição.

Carioca, arquiteto por formação e fotógrafo por opção, foi em Brasília que desenvolveu sua carreira: "Sempre me perguntei por que mudei de profissão. Comecei a buscar na fotografia algum sentido. Descobri que a imagem é minha vida. Sou encantado pela palavra, adoro escrever, mas a imagem para mim é mais forte." ${ }^{\prime 1}$ Foi na prática que desenvolveu sua teoria sobre a fotografia e, como bom fotógrafo, passou a ter uma visão bastante particular, se não peculiar, sobre o ato fotográfico. Fotografar para ele nada mais é do que aprender a ver o que é definido como banalidade: "O difícil é lidar, com sensibilidade, com as ocorrências banais, como o dia-a-dia.”2 A fotografia é considerado um hábito visual, forma de registro, de memória. E, quando falamos de registro, não se trata do ponto de vista estético, mas do ponto de vista de funcionalidade. Luis Humberto

\footnotetext{
* Texto publicado no livro Luis Humberto - a luz e a fúria, da Coleção Brasilienses (vol.3). Brasília: Edição independente, 2008.

** Jornalista e crítica de fotografia. É mestre em Comunicação e Artes e doutora em Psicologia Social. Autora dos livros Imagens da Fotografia Brasileira I e Imagens da Fotografia Brasileira II. Desde 2003, organiza, com Thales Trigo, a Coleção Senac de Fotografia. Teve "a honra e o prazer" de contar com Luis Humberto na Banca de Avaliação de sua tese de doutoramento, defendida na PUC/SP em 2001.

${ }^{1}$ Entrevista a Simonetta Persichetti. Publicada no livro Imagens da Fotografia Brasileira I. São Paulo: Estação Liberdade/Senac, 2000.

${ }^{2}$ Entrevista a Simonetta Persichetti. Publicada no livro Luis Humberto, da Coleção Senac de Fotografia (vol.1). São Paulo: Senac, 2003.
} 
entende a fotografia como forma reveladora de olhar com novas possibilidades interpretativas, novas maneiras de organizar a realidade.

Se entendermos sua maneira de pensar fotografia, compreendemos que, para ele, as imagens realizadas no cotidiano pessoal têm a mesma importância daquelas realizadas no cotidiano ou na história de um país. Átimos que não se repetem e que nos instigam a perceber, a olhar, a redefinir. Como se ele nos dissesse: "Nada é o que aparenta ser."

Começou a esboçar essas constatações sobre o papel da fotografia no livro Universo e Arrabaldes, publicado em 1983, e sistematizou-as, em 2000, quando definiu a fotografia como a “poética do banal”. "Não é preciso esperar um grande acontecimento para começar a fotografar. Ela está no cotidiano, pulsando, esperando por um olhar revelador”, ensina Luis Humberto.

Mas, atenção! Se ele fala em banalidade, de forma nenhuma quer dizer superficialidade. Basta olharmos as imagens que fez nos anos 70, quando todo cuidado era pouco, para perceber que, em lugar da pose oficial, seu olhar buscava alternativas, como a expressão cansada de um ministro, a de outros dois confabulando, enquanto uma faxineira espanava os móveis, ou o beija-mão ao presidente da República no final do ano. Ou seja, busca os momentos em que de alguma maneira o “escondido” se revela, quando todos se despem das máscaras e acreditam que estão fora das luzes e do olhar da imprensa. Surge, então, a eloqüência das pequenas coisas: “A informação visual não se resume na confirmação do óbvio, é antes uma porta de entrada para novas paisagens e novas reflexões.”3

É, portanto, coerente que a teoria dele sobre fotografia seja inseparável do dia-a-dia, do que realmente acontece na vida de um fotógrafo. Sua vida acadêmica é tão importante e fundamental quanto suas fotografias. Luis Humberto foi responsável pela formação teórica de muitos fotojornalistas. Começou a escrever, em 1967, numa revista paulista chamada Mirante das Artes, editada por Pietro Maria Bardi, diretor do Museu de Arte de São Paulo (Masp). Teve textos e reflexões publicados

\footnotetext{
${ }^{3}$ Entrevista a Simonetta Persichetti. Publicada no livro Luis Humberto, da Coleção Senac de Fotografia (vol.1). São Paulo: Senac, 2003.
} 
também pelas revistas Iris e Fotóptica. Sempre se preocupou com a reflexão, com a educação por meio do olhar. Sabe da importância da formação de um fotógrafo: "Processos de criação não são deflagrados por iluminações súbitas, de origens misteriosas, destinadas a indivíduos privilegiados, mas pelas circunstâncias de momentos históricos, restritivos ou generosos, determinados por uma conjuntura política, econômica e cultural”, escreveu em seu livro Fotografia, a poética do banal ${ }^{4}$. Nem quando foi expulso da faculdade pelo AI-5 (e reintegrado pela anistia em 1988), deixou de falar, de formar, de instigar os fotojornalistas a refletir sobre sua produção. Fundamental foi, também, seu trabalho como editor de fotografia do Jornal de Brasília, em 1973. Ao editar as páginas, ensinava a ver, a escolher, a decidir sobre a imagem mais adequada para uma matéria. Diferente do que acontece hoje na maior parte da imprensa brasileira, em que editar passou a ser, apenas, selecionar o que pode ficar bonito numa página. Ilustra-se uma matéria quase como se a imagem fosse um adorno. Luis Humberto escolhia ou selecionava a imagem que fazia sentido, que tinha algo a acrescentar. A fotografia, como o texto, era jornalismo.

Hoje, aos 73 anos, com 45 de carreira e há mais de 20 fora do fotojornalismo, Luis Humberto continua fotógrafo, continua teórico, continua pensando e falando sobre fotografia, como pesquisador associado do Departamento de Pós-Graduação da Faculdade de Comunicação da UnB. E, como sempre, continua fundamental para que possamos ver com novos olhos questões que acreditamos já terem sido superadas.

Lançado recentemente, o livro Luis Humberto: a luz e a fúria (Coleção Brasilienses), organizado por Carlos Marcelo, resgata a trajetória imagética do fotógrafo e traz textos de Nahima Maciel e ensaios críticos de Marcelo Feijó e Simonetta Persichetti (este reproduzido acima). De Brasília, Luis Humberto contou como foi fazer este livro e outras coisas sobre fotojornalismo e fotografia atual. Acompanhe nas próximas páginas a entrevista concedida a Simonetta Persichetti.

\footnotetext{
${ }^{4}$ HUMBERTO, Luis. Fotografia, a poética do banal. Brasília/São Paulo: UnB/Imprensa Oficial do Estado, 2000.
} 


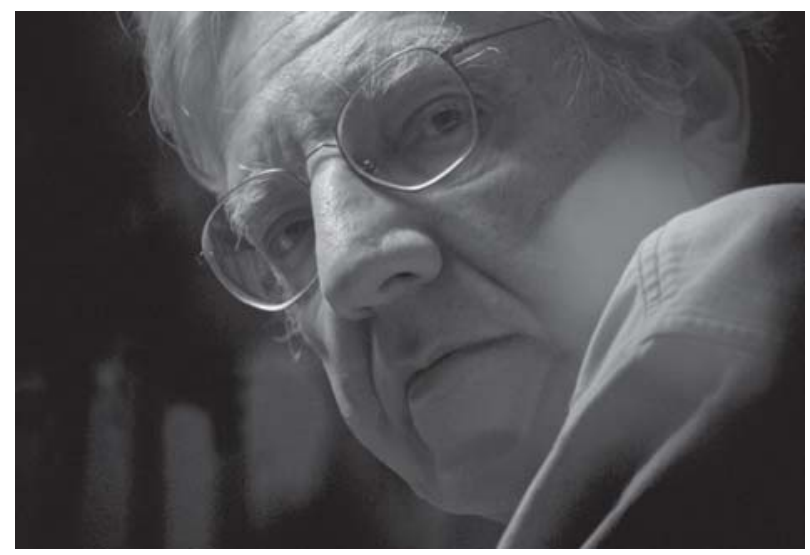

Luis Humberto

Foto: cortesia da editora

\section{Entrevista}

Simonetta - Antes de mais nada, como foi para você abrir seus arquivos, rever imagens e iniciar a feitura deste livro?

Luis Humberto - Foi bom, resultado do esforço e das relações de alguns amigos. Foi uma espécie de psicanálise amadora. Reencontrar fotos e fatos e refletir sobre eles. É muito interessante rever estas coisas à distância do tempo. Foram dois anos de pesquisas feitas pelo Carlos Marcelo e com entrevista da Nahima Maciel. Deixei por conta deles a edição e tudo mais, afinal era um livro deles sobre mim. Mas isso me permitiu reencontrar uma série de fotografias, rever imagens para as quais na época não havia dado a mínima bola e que agora voltam com um novo sentido e significado.

Simonetta - Você fotografou muitas coisas, mas ficou conhecido como fotojornalista. Isto te incomoda?

Luis Humberto - Este reconhecimento como fotojornalista acontece de forma mais efetiva em São Paulo, talvez pelas revistas com as quais colaborei. Mas me incomoda sim. Sou fotógrafo e o jornalismo foi uma parte de minha vida como fotógrafo. A fotografia oferece 
possibilidades infinitas. Tenho um longo ensaio sobre paisagem doméstica, por exemplo, que é casa desabitada, são fragmentos de uma casa, muito diferente da fotografia doméstica onde fotografei minha família. Além disso, tenho um longo trabalho sobre o cerrado. Mas por estes trabalhos as pessoas se interessam menos.

Simonetta - Mas você ajudou a criar um código, ou nos mostrou uma maneira de entender o que é o fotojornalismo ou o que era fazer fotojornalismo nos anos da ditadura...

Luis Humberto - Na verdade eu desenvolvi uma maneira de sair dos limites. Ou seja, havia na época a liturgia do cargo. Todos diziam o que e como você tinha que fotografar. Fomos criando saídas, para lugares mal-iluminados, para o não uso do flash que deixava tudo chapado e com uma mesma cara. Passei a utilizar preferencialmente a iluminação das janelas, a enteder luz. Isso graças também ao Rembrandt - grande Rembrandt, que foi muito inspirador para mim. Além disso, devíamos trabalhar com velocidades muito baixas. Enfim foi uma maneira ou uma forma de linguagem diferenciada.

Simonetta - Então, você é fotojornalista. Ou foi um dia fotojornalista?

Luis Humberto - Antes de mais nada sou fotógrafo. Isso significa ter uma atitude diferenciada frente à vida. Também fui fotojornalista que é a fotografia de investigação e descoberta.. Mas sem dúvida a fotografia me ensinou a ver as coisas de outro modo.

Simonetta - De fotógrafo para um pensador da imagem. Como foi este passo?

Luis Humberto - Quando fiz a opção pela fotografia, nos anos 60, foi uma atitude muito mal aceita. Como se a profissão estivesse num nível inferior às outras. Afinal, eu deixava de ser arquiteto, ou "doutor" para ser fotógrafo. Tinha dificuldade em fazer com que as pessoas aceitassem. Teve gente que me virou a cara, outros que achavam que eu estava passando necessidades. Ninguém entendeu que a minha opção foi 
uma escolha absolutamente passional. Foi paixão. Isso me levou então a escrever sobre fotografia. Meu primeiro artigo foi publicado, em 1967, numa revista do professor Pietro Maria Bardi ${ }^{1}$ : O Mirante das Artes. É um artigo que nem gosto de mostrar, pois lendo-o hoje vejo que está completamente equivocado. Mas de alguma maneira foi a forma que encontrei de pensar imagem. Ao escrever apareciam as questões.

Simonetta - Mas você acha que houve uma mudança no seu fotografar depois que você começou a escrever ou vice-versa, suas fotos instigaram seus artigos?

Luis Humberto - Uma questão alavancava a outra. Não acredito que possamos nos separar desta forma tão distinta. Exprimi meu pensamento sobre fotografia durante anos em revistas como a Íris e a Fotóptica, de forma livre, sem obrigações, sem compromissos. Discutia o que me incomodava.

Simonetta - E aí também encontramos o Luis Humberto professor $^{2}$...

Luis Humberto - Pois é. Posso dizer que sou uma pessoa de muita sorte. Na minha vida profissional uma coisa encadeou na outra.

Simonetta - Sim, mas o que eu queria dizer é que você ajudou no desenvolvimento da linguagem fotográfica e na dos fotógrafos.

Luis Humberto - Foram dois momentos diferentes o primeiro e quando voltei para a Universidade nos anos $80^{3}$. Neste momento percebi uma dispersão muito forte por parte dos alunos, a indústria cultural tomando conta de tudo, ocupando espaço e não permitindo a reflexão. Ofereci duas disciplinas então: "Política Cultural” onde discutia as questões sociais e “Análise da Imagem”, que se transformou num espaço para a

\footnotetext{
${ }^{1}$ Pietro Maria Bardi (1900-1999), jornalista, historiador e crítico de arte fundou em 1947, com Assis Chateaubriand, o Museu de Arte de São Paulo (MASP) que dirigiu até 1996.

${ }^{2}$ Atualmente é pesquisador associeado do Departamento de Pós-Graduação da Faculdade de Comunicação da UnB.

${ }^{3}$ Co-fundador da UnB e do Instituto de Artes da instituição. Saiu da Universidade em 1966, retornando apenas nos anos 80 .
} 
experimentação. Como não havia uma ementa pré-existente me senti muito livre para desenvolver os dois cursos o que foi muito bom, pois pudemos discutir várias coisas e pensar o ato fotográfico.

Simonetta - Bom em relação a quando você começou hoje encontramos mais cursos de fotografia e mais pessoas aprendendo a pensar imagem...

Luis Humberto - Isto é verdade. Quando eu comecei - ou melhor, voltei - havia apenas o Boris Kossoy, eu, a Stefania Brill e o Moracy de Oliveira que pensavam a fotografia. Hoje é diferente, encontramos várias pessoas que pensam a fotografia, temos até mestrado em fotografia. Ou seja, hoje, finalmente, a fotografia não é vista penas como uma parte da arte, mas como parte integrante de uma esfera do conhecimento. Deixouse de lado um pouco a técnica, embora ela seja fundamental.

Simonetta - E o fotojornalismo hoje. Como você o vê?

Luis Humberto - Existem talentos interessantes. Mas o que eu vejo é que existe um processo onde tudo fica pasteurizado, muito igual. $\mathrm{O}$ que eu acho que falta é alguém que dê um tranco e mude esta história. Na verdade é isso que tentamos fazer há 30 anos.

Simonetta - Você continua fotografando ainda hoje?

Luis Humberto - Continuo, mas bem menos que antigamente por razões pessoais. Mas tenho me divertido com uma câmera digital, descobrindo suas particularidades.

Simonetta - Se você pudesse fazer um saldo de tua vida de fotógrafo o que você diria?

Luis Humberto - Que foi uma trajetória feliz! Tinha tudo para não dar certo e deu! Houve um momento que achei que nada daria certo. Mas descobri que quando você é movido à paixão, tudo se ilumina. O que não podemos deixar de fazer é estudar, pesquisar, e acima de tudo, ver. 